\title{
Types of Competitive Advantage and Analysis
}

\author{
Wang, Wen-Cheng \\ Department of Business Management, Hwa Hsia Institute of Technology \\ 111 Gong Jhuan Rd., Chung Ho, Taipei, Taiwan, R.O.C \\ Tel: 886-2-8941-5022Ｅ-mail: wcwang@cc.hwh.edu.tw \\ Lin, Chien-Hung \\ Department of Business Management, Hwa Hsia Institute of Technology \\ 111 Gong Jhuan Rd., Chung Ho, Taipei, Taiwan, R.O.C \\ Tel: 886-2-8941-5022 E-mail: davidamy22@yahoo.com.tw \\ Chu, Ying-Chien \\ Department of Tourism and Leisure, National Penghu University \\ 300 Liu-Ho Rd., Makung city, Penghu, Taiwan, R.O.C \\ Tel: 886-6-926-4115 E-mail: verna323@npu.edu.tw
}

Received: October 27, 2010 Accepted: December 20,2010 doi:10.5539/ijbm.v6n5p100

\begin{abstract}
The internal sources of competitive advantage cover a wide range of areas. The important competitive advantages behind an organization are not merely determined by its external factors. The internal sources of competitive advantage of a firm have been considered as crucial factors to success. The research looks at the extensive literature in relation to competitive advantage. The formation of main theories in literature review was illustrated by the concepts of competitive advantages through proper management action when managing the structure, process, culture and people of an organization. Therefore, the aim of competitive advantage recognition is connect with resources, capabilities and core competencies of the organization. By means of exploring and understanding the theories in literature review, to underpin the research.
\end{abstract}

Keywords: Competitive advantage, Organization, Culture, Resources

\section{Introduction}

A competitive advantage exists when the firm is able to deliver the same benefits as competitors but at a lower cost (cost advantage), or deliver benefits that exceed those of competing products (differentiation advantage). Competitive advantage is a theory that seeks to address some of the criticisms of comparative advantage. Competitive advantage theory suggests that states and businesses should pursue policies that create high-quality goods to sell at high prices in the market. Porter (1995) emphasizes productivity growth as the focus of national strategies. Competitive advantage rests on the notion that cheap labor is ubiquitous and natural resources are not necessary for a good economy. Competitive advantage is necessary for satisfied customers who will receive higher value in delivered products for higher income what the owners request from management and such requirements can be fulfilled with organization of production, higher application and as low as possible production costs (Ranko, Berislav ,and Antun, 2008). Barney (1991) suggested that the resources that are scarce and valuable at the same time can create competitive advantage, and if these resources are also difficult to duplicate, substitute and hard to deliver, they can sustain the advantage. Competitive advantage occurs when an organization acquires or develops an attribute or combination of attributes that allows it to outperform its competitors. These attributes can include access to natural resources, such as high grade ores or inexpensive power, or access to highly trained and skilled personnel human resources.

Above writings signify competitive advantage as the ability to stay ahead of present or potential competition, thus superior performance reached through competitive advantage will ensure market leadership. Also it 
provides the understanding that resources held by a firm and the business strategy will have a profound impact on generating competitive advantage. Differentiation strategy is usually developed around many characteristics such as product quality, technology and innovativeness, reliability, brand image, firm reputation, durability, and customer service, which must be difficult for rivals to imitate (Mose, 2010). A firm implementing a differentiation strategy is able to achieve a competitive advantage over its rivals because of its ability to create entry barriers to potential entrants by building customer and brand loyalty through quality offerings, advertising and marketing techniques. Thus, a firm that implements a differentiation strategy enjoys the benefit of price-inelastic demand for its product or service. In addition, Barney (1991) emphasized the ability of firms to establish entry obstruction in order to prevent imitation from its competitors and take advantage of their resource for the purpose of sustaining the international competitive advantage. In this paper is going to probe the internal factors of managerial action to gain competitive advantage. Discussion about the technology and innovation, human resources, organizational structure resources factors to see how they contribute to the competitive advantage and the relationships in between.

\section{Sources of competitive advantage}

\subsection{Technology and innovation for competitive advantage}

The term innovation has a commercial aspect different from scientific research. Innovation has a very important role in economic development of countries, because innovative companies, through commercializing their research and development results, are creating new and nonexistent value. Furthermore these same companies are getting an important share of the newly created value. By this way, they are mainly creating wealth for themselves, for their country and for the world. Innovation includes both product / service and process innovations. Product innovations are products that are perceived to be new by either the producer or the customer; the latter includes both end-users and distributors. Process innovation refers to new processes which either reduce the cost of production or enable the production of new products (Harmsen, Grunert, and Declerck, 2000). In spite of the increasing importance of innovation and the role played by technological capabilities in a firm's growth trajectory, little is known how technological innovation in different organizations is driven by their technology strategy, the plan that guides the accumulation and deployment of technological resources and capabilities (Dasgupta, Sahay, and Gupta, 2009).

That is, the most innovative firms engage in a continual search for better products, services, and ways of doing things. They try to continuously upgrade their internal capabilities and other resources. Aggregate innovative capacity of a nation is derived from the collective innovative capacity of its firms. The more innovative firms a nation has, the stronger that nation's competitive advantage. Innovation also promotes productivity, the value of the output produced by a unit of labor or capital. The more productive a company is, the more efficiently it uses its resources. The more productive the firms in a nation are, the more efficiently the nation uses its resources (Knight, 2007). Innovation and entrepreneurial activity are the engines of long-run economic growth. Often, entrepreneurs first commercialize innovative new products and processes, and entrepreneurial activity provides much of dynamism in an economy. For example, the economy of the United States has benefited greatly from a high level of entrepreneurial activity, which has resulted in rapid innovation in products and processes.

\subsection{Human resources for competitive advantage}

Human resources are a term used to describe the individuals who comprise the workforce of an organization, although it is also applied in labor economics to, for example, business sectors or even whole nations. Firms can develop this competitive advantage only by creating value in a way that is difficult for competitors to imitate. Traditional sources of competitive advantage such as financial and natural resources, technology and economies of scale can be used to create value. However, the resource-based argument is that these sources are increasingly accessible and easy to imitate. Thus they are less significant for competitive advantage especially in comparison to a complex social structure such as an employment system. If that is so, human resource policies and practices may be an especially important source of sustained competitive advantage (Jackson and Schuler, 1995).

Within the best practices approach to strategic HRM, the first practice, internal career opportunities, refers to the organizational preference for hiring primarily from within. Second, training systems refers to whether organizations provide extensive training opportunities for their employees or whether they depend on selection and socialization processes to obtain required skills. Third, appraisals are conceptualized in terms of outcome-based performance ratings and the extent to which subordinate views are taken into account in these ratings. Fourth, employment security reflects the degree to which employees feel secure about continued employment in their jobs. Although formalized employment security is generally on the decline, organizations may have either an implicit or an explicit policy. Fifth, employee participation, both in terms of taking part in 
decision making and having opportunities to communicate suggestions for improvement, has emerged as a strategic HRM practice. Sixth, job description refers to the extent jobs are tightly and clearly defined so that employees know what is expected of them. Finally, profit sharing reflects the concern for overall organizational performance on a sustainable basis. (Akhtar1, Ding, and Gloria, 2008) Ulrich and Yeung (1989) argue that the future HR professional will need four basic competencies to become partners in the strategic management process. These include business competence, professional and technical knowledge, integration competence and ability to manage change. Human Resources seeks to achieve this by aligning the supply of skilled and qualified individuals and the capabilities of the current workforce, with the organization's ongoing and future business plans and requirements to maximize return on investment and secure future survival and success. In ensuring such objectives are achieved, the human resource function purpose in this context is to implement the organization's human resource requirements effectively but also pragmatically, taking account of legal, ethical and as far as is practical in a manner that retains the support and respect of the workforce.

\subsection{Organizational structure for competitive advantage}

Organizations are a variant of clustered entities. An organization can be structured in many different ways, depending on their objectives. The structure of an organization will determine the modes in which it operates and performs. Organizational structure allows the expressed allocation of responsibilities for different functions and processes to different entities such as the branch, department, workgroup and individual. Individuals in an organizational structure are normally hired under time-limited work contracts or work orders, or under permanent employment contracts or program orders. Also, this correlate of changing structures and processes is reinforced by increased competitive pressure forcing companies to focus on their core competencies, redrawing their boundaries around what constitute and support their competitive advantage. This pressure is reflected in the changing organizational structures from a functional to a multi-divisional one, through the shifting of business towards smaller, decentralized units. When superior skills or resources exist outside the company, firms are making increased use of strategic alliances to supplement and sometimes enhance their own competencies. Whenever by alliances, outsourcing or downscoping, firms appear to be drawing in their boundaries around narrower spheres of activities (Petison and Johri, 2006).

An effective organizational structure shall facilitate working relationships between various entities in the organization and may improve the working efficiency within the organizational units. Organization shall retain a set order and control to enable monitoring the processes. Organization shall support command for coping with a mix of orders and a change of conditions while performing work. Organization shall allow for application of individual skills to enable high flexibility and apply creativity. When a business expands, the chain of command will lengthen and the spans of control will widen. When an organization comes to age, the flexibility will decrease and the creativity will fatigue. Therefore organizational structures shall be altered from time to time to enable recovery. If such alteration is prevented internally, the final escape is to turn down the organization to prepare for a re-launch in an entirely new set up.

\section{Strategies for Competitive Advantage}

The differentiation and cost leadership strategies seek competitive advantage in a broad range of market or industry segments. By contrast, the differentiation focus and cost focus strategies are adopted in a narrow market or industry. A firm positions itself by leveraging its strengths. Porter (1985) has argued that a firm's strengths ultimately fall into one of two headings: cost advantage and differentiation. By applying these strengths in either a broad or narrow scope, three generic strategies result: cost leadership, differentiation, and focus. These strategies are applied at the business unit level. They are called generic strategies because they are not firm or industry dependent. The following Porter's generic strategies:

\subsection{Strategy - Differentiation}

This strategy involves selecting one or more criteria used by buyers in a market - and then positioning the business uniquely to meet those criteria. This strategy is usually associated with charging a premium price for the product - often to reflect the higher production costs and extra value-added features provided for the consumer. Differentiation is about charging a premium price that more than covers the additional production costs, and about giving customers clear reasons to prefer the product over other, less differentiated products. Firms that succeed in a differentiation strategy often have the following internal strengths:

- Access to leading scientific research.

- Highly skilled and creative product development team.

- Strong sales team with the ability to successfully communicate the perceived strengths of the 
product.

- Corporate reputation for quality and innovation.

\subsection{Strategy - Cost Leadership}

With this strategy, the objective is to become the lowest-cost producer in the industry. Many (perhaps all) market segments in the industry are supplied with the emphasis placed minimising costs. If the achieved selling price can at least equal (or near) the average for the market, then the lowest-cost producer will (in theory) enjoy the best profits. This strategy is usually associated with large-scale businesses offering standard products with relatively little differentiation that are perfectly acceptable to the majority of customers. Occasionally, a low-cost leader will also discount its product to maximise sales, particularly if it has a significant cost advantage over the competition and, in doing so, it can further increase its market share. Firms that succeed in cost leadership often have the following internal strengths:

- Access to the capital required making a significant investment in production assets; this investment represents a barrier to entry that many firms may not overcome.

- Skill in designing products for efficient manufacturing, for example, having a small component count to shorten the assembly process.

- High level of expertise in manufacturing process engineering.

- $\quad$ Efficient distribution channels.

\subsection{Strategy - Differentiation Focus}

In the differentiation focus strategy, a business aims to differentiate within just one or a small number of target market segments. The special customer needs of the segment mean that there are opportunities to provide products that are clearly different from competitors who may be targeting a broader group of customers. Companies following focused differentiation strategies produce customised products for small market segments.

They can be successful when either the quantities involved are too small for industry-wide competitors to handle economically, or when the extent of customisation (or differentiation) requested is beyond the capabilities of the industry-wide differentiator. The important issue for any business adopting this strategy is to ensure that customers really do have different needs and wants - in other words that there is a valid basis for differentiation and that existing competitor products are not meeting those needs and wants.

\section{Strategy - Cost Focus}

Companies that compete by following cost leadership strategies to serve narrow market niches generally target the smallest buyers in an industry (those who purchase in such small quantities those industry-wide competitors cannot serve them at the same low cost). Here a business seeks a lower-cost advantage in just on or a small number of market segments. The product will be basic - perhaps a similar product to the higher-priced and featured market leader, but acceptable to sufficient consumers.

\section{Conclusion}

This paper has proposed for exploring the relationship between competitive advantage and technological innovation. Competitive advantage cannot work in isolation to lead to innovation. It should be complemented by various organizational factors for competitive advantage. Technology strategy of an organization can be understood by analyzing the technological innovation process. The paper highlights the importance of combining competitive advantage and sources of analysis. HR and training \& development policies can be modulated so as to support the technology strategy for innovations. A synergy between management of technology and management of softer aspects would benefit the organization.

Keeping the advantage require that the sources are broaden and their sources enhanced, lifting them in the hierarchical scale to more sustainable types. Also it requires changes, it requires that the company exploits the tendencies of the sector instead of ignoring them; it requires that the company invest in order to block the routes which represent a path for attack. The company might have top destroy old advantages in order to create new ones of high order level (Porter, 1990). To sum up, it is reasonable for a firm to understand the sources of competitive advantage first as it help a firm to evaluate itself the probability of acquiring the needed competitive advantage. It is believed that one can have enough ability to analysis the internal and external factors that may help a firm to gain the competitive advantage. It is worth mentioned that each generic source of competitive advantage is not necessary to be independent, instead, can work together to create the most competitive advantage for a firm. 


\section{References}

Akhtar1, S., Ding1, D. Z., \& Gloria L. G. (2008). Strategic HRM practices and their impact on company performance in Chinese enterprise. Human Resource Management, 47(1), pp15-32.

Barney, J. B. (1991). Firm Resources and Sustained Competitive Advantage. Journal of Management Science, 17(1), pp.99-120.

D. Meeta, A. Sahay, \& R. Gupta. (2009). Technological Innovation and Role of Technology Strategy: Towards Development of a Model. 9th Global Conference on Business \& Economics.

Gary Knight. (2007). International Business Strategy and Managerial Skills. Prentice Hall.

Harris, L., Colis, A.M., \& Dickson, K. (2000). Building innovation networks: Issues of strategy and expertise. Technology Analysis and Strategic Management, 12(2).

Jackson, S. E., \& Schuler, R. S. (1995). Strategic Human Resource Management. Blackwell Science.

Moses, A. (2010). Business Strategy and Competitive Advantage in Family Businesses in Ghana: The Role of Social Networking Relationships. Conference on Entrepreneurship in Africa.

Petison, P., \& Johri, L. M. (2006). Driving harmony: philosophy of Toyota Motor Thailand. Strategic Direction, 22(11), pp.3 - 5.

Porter, M.E. (1985). Competitive Advantage. New York, M.E. (ed.)

Porter, M.E. (1990). The competitive advantage of nations. Harvard Business Review.

Ranko, S., Berislav, B., \& Antun, S. (2008). Document management system as source of competitive advantage. New Ways in Manufacturing Engineering'2008.

Ulrich, D., \& Yeung, A. (1989). A Shared Mindset. Personnel Administrator, pp117-134. 